IdeAs

Idées d'Amériques

$7 \mid 2016$

Cinéma et histoire dans les Amériques

\title{
Cine e historia en las Américas
}

Cinema and History in the Americas

Cinéma et histoire dans les Amériques

Ignacio Del Valle Dávila y Eduardo Morettin

Traductor. Marta Gómez

\section{OpenEdition}

Journals

Edición electrónica

URL: https://journals.openedition.org/ideas/3113

DOI: 10.4000/ideas.3113

ISSN: 1950-5701

Este artículo es una traducción de:

Cinéma et histoire dans les Amériques - URL : https://journals.openedition.org/ideas/1503 [

Otras traducciones del artículo:

Cinema and History in the Americas - URL : https://journals.openedition.org/ideas/3103 [

Cinema e história nas Américas - URL : https://journals.openedition.org/ideas/3144 [pt]

Editor

Institut des Amériques

Referencia electrónica

Ignacio Del Valle Dávila y Eduardo Morettin , «Cine e historia en las Américas», IdeAs [En línea], 7| 2016, Publicado el 03 junio 2016, consultado el 19 octubre 2022. URL: http://

journals.openedition.org/ideas/3113; DOI: https://doi.org/10.4000/ideas.3113

Este documento fue generado automáticamente el 19 octubre 2022.

\section{(c) $)(9)$}

Creative Commons - Atribución-NoComercial-SinDerivadas 4.0 Internacional - CC BY-NC-ND 4.0 https://creativecommons.org/licenses/by-nc-nd/4.0/ 


\title{
Cine e historia en las Américas
}

\author{
Cinema and History in the Americas \\ Cinéma et histoire dans les Amériques \\ Ignacio Del Valle Dávila y Eduardo Morettin \\ Tradución : Marta Gómez
}

1 El cine es una de las principales expresiones artísticas y culturales de los siglos XX y XXI, además de un poderoso medio de comunicación de masas. Sus características lo convierten en una fuente primaria de gran interés para el estudio de proyectos políticos e imaginarios colectivos en el seno de diferentes comunidades y en periodos históricos determinados. Por ello, son muchos los investigadores que se han interesado por la relación entre cine e historia.

El objetivo del dossier «Cine e historia en las Américas» es entender el papel que ha desempeñado el cine en la representación del pasado histórico de distintos países del continente americano. Con este estudio también queremos presentar diversas propuestas prácticas acerca de las formas de utilizar el cine como fuente de estudio de la historia. Así pues, los artículos ofrecen una serie de análisis que abarcan tanto los inicios del cine como sus tendencias más recientes: el llamado cine mudo, el paso del lenguaje visual al lenguaje audiovisual, el desarrollo del melodrama y del cine histórico, el cine de autor de los años 60 , el cine militante de los años 60 y 70, y los documentales autobiográficos de los últimos veinte años.

3 Es imposible resumir de forma exhaustiva y en pocas páginas las principales contribuciones teóricas que abordan el cine desde una perspectiva histórica. Por ello nos limitaremos a reseñar algunos puntos de inflexión dentro de la evolución de este campo de investigación. En términos generales, podemos afirmar que tanto las películas documentales como las cintas de ficción han tardado décadas en ser consideradas fuentes legítimas para el estudio de la historia y ello a pesar de su importante nivel de penetración -sobre todo en el caso de la ficción- como entretenimiento de masas, asociado a su doble naturaleza artística e industrial. Solo a partir de los trabajos de Marc Ferro en los años 70, materializados en la obra Cine e historia, publicada en 1977, empiezan a sistematizarse una serie de principios 
metodológicos sobre la utilización del cine como fuente de estudio para el historiador. Según Ferro, el análisis de las imágenes en movimiento podría permitir lanzar un «contraanálisis de la sociedad» al revelar zonas de realidad latente, «zonas no visibles del pasado de las sociedades, revelando, por ejemplo, las autocensuras y lapsus de una sociedad» (Ferro M., 2009: 27). A pesar de que esta teoría ha sido ampliamente debatida y criticada en los últimos treinta años, la defensa que Ferro hace del valor de la imagen en movimiento como «documento histórico» $\mathrm{y}$ «agente de la historia» en una sociedad que la produce y consume sigue siendo pertinente para la investigación de las relaciones entre cine e historia (Ferro M., 2009: 17).

4 Este campo de estudio se enriqueció rápidamente con la aparición de los libros de Pierre Sorlin Sociología del cine (Sorlin P., 1977) y The Film in History: Restaging the Past (Sorlin P., 1980). Sorlin, especialmente atento a las relaciones entre el cine de ficción histórica y la historia como disciplina, ha intentado demostrar que la representación del pasado a través del cine deja entrever cuestiones políticas contemporáneas. Por otro lado, como el mismo autor ha reconocido, su interés por la semiótica en los años 80 como enfoque metodológico del análisis fílmico parece menos pertinente en la actualidad.

Durante la última década del siglo XX y las dos primeras del siglo XXI, los estudios sobre cine e historia se han ampliado y diversificado. Además de una revisión metodológica, ha habido numerosos trabajos que se han centrado en el análisis de una película o de un contexto específico y que han permitido confirmar la validez de los principios generales. En el contexto francés, Michèle Lagny ha reflexionado sobre el desarrollo de una metodología que, sin abandonar el análisis del texto fílmico, considera indispensable para su interpretación la inserción de dicho texto en su contexto cultural y tradición fílmica, más allá de la identificación de las condiciones políticas y económicas de su producción (Lagny M., 2009). Desde una perspectiva distinta, a partir de la constatación de la proliferación de películas de época, Pierre Beylot y Raphaëlle Moine empiezan a interesarse desde los años 80 por las relaciones entre el cine histórico de ficción y la idea de patrimonio histórico y cultural (Beylot $\mathrm{P}$., y R. Moine, 2009). Sylvie Lindeperg, por su parte, acuña el concepto de «microhistoria en movimiento» para explicar su manera de abordar la cinta Noche y neblina (Alain Resnais, 1955). Su trabajo sobre este documental abarca tanto el análisis de las formas cinematográficas como el estudio minucioso del contexto en el que fue producido y difundido (Lindeperg S., 2007: 8). Antoine De Baecque, por otro lado, desarrolla el concepto de "cámara histórica» a través del cual busca demostrar que el cine puede considerarse una forma de historia dada su capacidad de representar el pasado, transformarse en archivo del pasado y lograr, por medio del montaje, nuevas formas de reflexión sobre el pasado reconstruido o preservado en el celuloide (De Baecque A., 2008: 13).

6 Del otro lado del Atlántico, los trabajos de Robert Rosenstone tuvieron una enorme repercusión. Según Rosenstone, el cine histórico, incluidas las ficciones, modelan nuestra conciencia histórica, como también lo hacen otros medios audiovisuales. El principal objetivo del autor es investigar de qué modo el cine crea un mundo histórico (Rosenstone R., 2010). En su intento por entender cómo se construye el saber sobre el pasado a través del cine, llega a equiparar el trabajo del cineasta con el del historiador, pese a que las reglas de interacción de las obras cinematográficas con el pasado son distintas a las de la historia escrita (Rosenstone R., 2010: 22). La tesis de Rosenstone es 
que tanto la historia escrita como el cine son relatos construidos por convención dentro de los cuales es posible encontrar elementos imaginarios o irreales. De este modo, llega a incluir tanto la producción universitaria como las artes escénicas dentro de una categoría difusa constituida por relatos.

7 Cabe destacar asimismo la renovación experimentada en el ámbito de la historia del cine. A partir del Congreso de Brighton, celebrado en 1978 bajo la égida de la Federación Internacional de Archivos Fílmicos, la cercanía de las cuestiones aportadas por la historia cultural propiciaría la propuesta de un método de análisis fílmico que incluía la dimensión histórica. Como escribe Tom Gunning, uno de los participantes al congreso:

Si bien los métodos de análisis de películas como sistemas de significado difieren de los de las películas consideradas como mercancías, dichos análisis no se excluyen entre sí, ni tampoco son, en última instancia, independientes. [...] Debemos desarrollar métodos de análisis cinematográfico que incluyan la dimensión histórica. [...] Es hora de llevar a cabo una comparación diacrónica de las películas a lo largo de la historia (Gunning T., 1990: 86).

Rosenstone, Ferro y Sorlin son los principales autores con los que interactúan los investigadores latinoamericanos. Ello responde en cierta medida al hecho de que algunas de sus obras se hayan traducido al portugués y al español. Este campo de investigación ha empezado a desarrollarse especialmente en Brasil, donde desde mediados de los años 90 prolifera una literatura científica ${ }^{1}$. Cabe destacar los libros História e cinema (Capelato M. H., Morettin, E., Napolitano M. et al., 2007), Cinematógrafo: um olhar sobre a história (Nóvoa J., Biscouto Fressato S. y Feigelson K., 2009) o História e documentário (Morettin E., Napolitano M. y Kornis M., 2012); História e Audiovisual, número especial de la revista Estudos Históricos (Kornis M., 2012) y el dossier As imagens no tempo e os tempos da imagem de la revista Histórica, Questões \& Debates (Bastos Kern M. L. y Kaminski R., 2014). Pueden mencionarse también diversas monografías, tales como Canibalismo dos fracos (Freire Ramos A., 2002), sobre la cinta Os Inconfidentes (Joaquim Pedro de Andrade, 1972), y Humberto Mauro, Cinema, História (Morettin E., 2013), además de numerosos artículos, jornadas de estudio, congresos, seminarios y proyectos de investigación.

9 Cualquier película abre un diálogo con la sociedad y la época en la que ha sido realizada. Además, incorpora y moviliza los imaginarios e ideologías de una sociedad en conflicto, al tiempo que ejerce potencialmente una influencia sobre ellos como agente histórico. En este sentido, queremos incidir especialmente en cómo las películas analizadas contribuyen a construir imaginarios sociales y a defender discursos y proyectos políticos. Con el fin de abordar el cine como fuente para la historia, conviene tomar en consideración su especificidad artística, así como las características propias del lenguaje audiovisual. De lo contrario, nos arriesgamos a analizarlo con una metodología heredada de la escritura que resulta inadecuada para dar cuenta del cine como documento de su época. La cuestión central es precisamente reconocer el carácter específico del campo cinematográfico. Por ello, conviene subrayar la importancia del análisis fílmico como herramienta tanto para estudiar los documentos cinematográficos como para plantear cuestiones que sirvan para orientar la reflexión.

Los artículos del dossier abarcan tres zonas geográficas (América del Sur, el Caribe y Norteamérica) y cuatro áreas lingüísticas (hispana, portuguesa, anglófona y francófona). Hemos dado prioridad al estudio de casos nacionales para evitar el riesgo de caer en una visión generalista y poco profunda de la cuestión estudiada. Con todo, en 
el caso de determinadas experiencias cinematográficas relacionadas con el exilio y la migración, hemos considerado necesario no seguir estos criterios nacionales y proponer un planteamiento transnacional, dadas las exigencias de la cuestión en sí misma.

El dossier empieza por Brasil con los artículos de Ismail Xavier, Eduardo Morettin y Fernando Seliprandy. El primero analiza las relaciones entre alegoría histórica y compromiso en las películas del cineasta Glauber Rocha (activo de 1959 a 1980). Eduardo Morettin, por su parte, analiza las conexiones entre discurso histórico y discurso cinematográfico en la representación de la llegada de los colonizadores que realizó el cineasta Humberto Mauro en una época en la que el gobierno de Getúlio Vargas (1930-1945) buscaba una legitimación simbólica. Por último, Fernando Seliprandy estudia las convergencias y divergencias entre dos documentales sobre el guerrillero Carlos Marighella: Marighella: retrato falado do guerrilheiro (Silvio Tendler, 2001) y Marighella (Isa Grinspum Ferraz, 2011).

12 Las películas de ficción de los años 70 y 80 son el tema principal de dos artículos sobre el cine argentino. En el primero, Ignacio Del Valle Dávila analiza, a partir de la cinta $\mathrm{El}$ santo de la espada (Leopoldo Torre-Nilsson, 1970), las relaciones entre el cine histórico y el proyecto ideológico de la dictadura autodenominada «Revolución Argentina» (1966-1973) a propósito del héroe de la independencia José de San Martín (1778-1850). Ana Laura Lusnich, por su parte, estudia la preeminencia de alegorías y metáforas en las películas producidas durante la última dictadura argentina (1976-1983) y comienzos del periodo posdictatorial (1983-1989) como reflexión sobre el terrorismo de Estado y el control social que marcaron aquella época. El análisis de Lusnich se centra en los largometrajes Los miedos (Alejandro Doria, 1980) y Hay unos tipos abajo (Rafael Filipelli y Emilio Alfaro, 1985).

13 Mariana Villaça aborda la relación entre la política cultural del gobierno cubano y el influyente Instituto Cubano de Arte e Industria Cinematográficos (ICAIC), mostrando asimismo los conflictos internos entre la dirección del instituto y algunos cineastas críticos en dos momentos especialmente tensos de la vida cultural de la isla: 1968 y principios de los años 70. Las cintas Coffea Arábiga (Nicolás Guillén Landrián, 1968) y $E l$ otro Francisco (Sergio Giral, 1973) son dos buenos ejemplos para analizar dichas relaciones.

14 Los artículos de Anne-Marie Paquet-Deyris, Sérgio Alpendre y Vincent Souladié abordan distintos momentos del cine de Estados Unidos. La primera estudia la representación cinematográfica del presidente Abraham Lincoln basándose en tres películas producidas entre principios y finales de los años 30: Abraham Lincoln (D. W. Griffith, 1930), El joven Lincoln (John Ford, 1939) y Lincoln en Illinois (John Cromwell, 1940). Los otros dos artículos sobre el cine de Hollywood examinan distintas relecturas que se han hecho del llamado sueño americano en momentos de crisis. En el primero de ellos, Sérgio Alpendre analiza las cintas Rocky (John G. Avildsen, 1976) y Fiebre del sábado noche (John Badham, 1977), a las que considera metáforas de una época de crisis del capitalismo tras el primer choque petrolero. En el segundo, Vincent Souladié realiza un análisis crítico, en materia de imágenes, comparando las películas de superhéroes producidas tras el 11 de septiembre de 2001 y los atentados contra las torres gemelas de Nueva York.

15 El estudio de las relaciones entre cine e historia en Norteamérica concluye con el análisis de una película inscrita en el espacio lingüístico francófono. En su artículo, 
Henri Gervaiseau analiza la cinta Le règne du jour (Pierre Perrault, 1967) explorando la forma en que la travesía entre espacios sociales y geográficos distantes dibujan un sentimiento de pertenencia territorial. El dossier se cierra con un artículo sobre experiencias cinematográficas ligadas a la migración y al exilio político, y más concretamente, sobre la circulación y los intercambios transnacionales. Jennifer Cazenave aborda la experiencia de la migración y el exilio en su estudio sobre dos películas-diario: Reminiscences of a Journey to Lithuania (Jonas Mekas, 1973) y Diary (David Perlov, 1973-1983).

16 El dossier en su conjunto ofrece una visión diversa y compleja de las relaciones entre cine e historia en el continente americano a través de casos específicos que incluyen el análisis tanto de contextos nacionales como de movimientos transnacionales. Queremos resaltar el hecho de que la perspectiva histórica que orienta estos estudios ha favorecido una productiva confluencia entre investigadores del cine procedentes de horizontes diversos. Esta orientación se ha traducido en la publicación dentro del dossier de textos redactados por especialistas en historia, estudios cinematográficos, comunicación y estética.

El lector podrá advertir fácilmente la interacción entre enfoques y temáticas de muchos de estos textos. Ismail Xavier y Ana Laura Lusnich hacen hincapié en la importancia de la alegoría para el cine, mientras Eduardo Morettin, Ignacio Del Valle Dávila y AnneMarie Paquet-Deyris se centran en los relatos fundacionales, Jennifer Cazenave y Henri Gervaiseau estudian el cine-ensayo, Anne-Marie Paquet-Deyris, Ignacio Del Valle Dávila y Fernando Seliprandy, el retrato hagiográfico, e Ismail Xavier y Mariana Villaça, las relaciones entre cine y proyectos revolucionarios.

18 A pesar de las múltiples problemáticas abordadas, todos los artículos se distinguen por la función central atribuida al análisis cinematográfico para comprender los fenómenos históricos en los que se enmarcan las obras estudiadas. No hemos considerado pertinente reducir la diversidad de propuestas a un número limitado de temáticas. No obstante, es posible plantear ciertas tendencias generales. Todas las propuestas abordan directamente la relación entre arte y política, en diferentes épocas y bajo distintos formatos. En este sentido, es interesante señalar cómo los trabajos sobre América Latina ponen de relieve el apogeo y la crisis del cine comprometido en proyectos revolucionarios, así como las relaciones más o menos tensas entre la producción cinematográfica y los gobiernos autoritarios. Por su parte, los artículos sobre Estados Unidos ponen el foco en el desarrollo del mercado cinematográfico -que desde principios del siglo XX se materializa en producciones cada vez más espectaculares- así como en la creación o revisión de relatos melodramáticos sobre los esfuerzos y ambiciones de héroes individuales. Dichos relatos se inscriben en un imaginario que comulga con la competitividad, la lucha por el ascenso social y el éxito como características fundamentales de la sociedad norteamericana.

El presente dossier se gestó a finales de 2013, cuando fue presentada una primera propuesta a la revista IdeAs. Se trata de una iniciativa vinculada al grupo de investigación "História e Audiovisual: circularidades e formas de comunicação» coordinado por los profesores Eduardo Morettin y Marcos Napolitano de la Universidad de São Paulo. Desde el principio, se decidió integrar a investigadores procedentes de diversos espacios universitarios con el fin de favorecer el intercambio internacional. Más allá de los vínculos institucionales, los autores tienen orígenes nacionales muy diversos (brasileño, francés, argentino, franco-brasileño, franco-estadounidense 
chileno-español), lo que puede interpretarse como un indicio de la creciente internacionalización de la investigación ${ }^{2}$. En definitiva, la pluralidad de enfoques en este dossier evidencia también la consolidación de un campo de estudio orientado hacia la reflexión sobre el cine y las ciencias humanas.

\section{BIBLIOGRAFÍA}

Bastos Kern, Maria Lúcia et Kaminski, Rosane (org.), As imagens no tempo e os tempos da imagem, História Questões \& Debates, $n^{\circ}$ 61, 2014.

Beylot, Pierre et Moine, Raphaëlle (dir.), Fictions patrimoniales, sur grand et petit écran, Bordeaux, PUB, 2009.

Capelato, Maria Helena ; Morettin, Eduardo ; Napolitano, Marcos ; Saliba, Elias Thomé (org.), História e cinema, São Paulo, Alameda, 2007.

De Baecque, Antoine et Chevalier, Philippe, Dictionnaire de la pensée du cinéma, Paris, Puf, 2012.

De Baecque, Antoine, L’histoire-caméra, Paris, Gallimard, 2008.

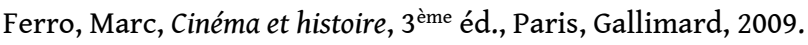

Freire Ramos, Alcides, Canibalismo dos fracos, Bauru, EDUSC, 2002.

Gunning, Tom, «Non-continuity, Continuity, Discontinuity. A Theory of Genres in Early Films», in Thomas Elsaesser (éd.), Space, Frame, Narrative, Londres, BFI Publishing, 1990.

«História e Audiovisual: circularidades e formas de comunicação» : http://

historiaeaudiovisual.weebly.com/teses-e-dissertaccedilotildees.html, page consultée le 26 mars 2016.

Kornis, Mônica Almeida (org.), História e Audiovisual, Estudos Históricos, vol. 26, n 51, 2013, http:// lisa.revues.org/index846.html, page consultée le 31 mars 2016.

Lagny, Michèle, «O cinema como fonte da história», in Jorge Nóvoa, Soleni Fressato et Kristian Feigelson, (dir.), Cinematógrafo: um olhar sobre a história, Salvador, EDUFBA; São Paulo, Edunesp, 2009, p. 99-132.

Lindeperg, Sylvie, «Nuit et brouillard» un film dans l'histoire, Paris, Odile Jacob, 2007.

Morettin, Eduardo ; Napolitano, Marcos, Kornis, Mônica Almeida (org.), História e documentário, Rio de Janeiro, Editora FGV, 2012.

Morettin, Eduardo, Humberto Mauro, Cinema, História, São Paulo, Alameda, 2013.

Nóvoa, Jorge ; Fressato, Soleni ; Feigelson, Kristian (org.), Cinematógrafo: um olhar sobre a história, Salvador, EDUFBA; São Paulo, Edunesp, 2009.

Rosenstone, Robert, A história nos filmes, os filmes na história, traduit de l'anglais (États-Unis) par Marcello Lino, [éd. orig. History on Film/Film on History, Harlow, Pearson Education] São Paulo, Paz e Terra, 2010 [2006]. 
Sorlin, Pierre, Sociologie du cinéma : ouverture pour l'histoire de demain, Paris, Aubier Montaigne, 1977.

Sorlin, Pierre, The film in history : restaging the past, Oxford, Basil Blackwell, 1980.

\section{NOTAS}

1. La lista de estos trabajos está disponible en la web del grupo de investigación «Historia y audiovisual: circularidades y formas de comunicación»: http://historiaeaudiovisual.weebly.com/ teses-e-dissertaccedilotildees.html, página consultada el 26 marzo de 2016.

2. Destaquemos en este sentido la trayectoria del profesor Ismail Xavier (su artículo abre el dossier), una de las principales referencias internacionales en el estudio de la obra de Glauber Rocha y de la alegoría en el cine latinoamericano y cuyos trabajos se han traducido ampliamente en Europa, Estados Unidos y América Latina. Sus aportaciones le han llevado a tener una entrada propia en el Diccionario del pensamiento del cine (De Baecque A. y Chevalier P., 2012).

\section{AUTORES}

\section{IGNACIO DEL VALLE DÁVILA}

De origen español y chileno, Ignacio Del Valle Dávila es doctor en cine por la Universidad de Toulouse - Jean Jaurès y ha realizado un posdoctorado en historia en la Universidad de São Paulo. Actualmente es profesor de tercer ciclo en el Instituto de Arte de la Universidad de Campinas (UNICAMP, Brasil), donde sigue investigando sobre el cine latinoamericano con una beca posdoctoral de CAPES (organismo brasileño de Coordinación del Perfeccionamiento del Personal de Nivel Superior). Autor de los libros Cámaras en trance: el nuevo cine latinoamericano, un proyecto cinematográfico subcontinental (Santiago de Chile, Editorial Cuarto Propio, 2014) o Le nouveau cinéma latino-américain: 1960-1974 (Rennes, PUR, 2015), es miembro del grupo de investigación CNPq «História e Audiovisual: circularidades e formas de comunicação» (Historia y Audiovisual: circularidades y formas de comunicación) y del consejo de redacción de la revista Cinémas d'Amérique latine.

\section{EDUARDO MORETTIN}

Eduardo Morettin es profesor de Historia audiovisual en la Escuela de Comunicaciones y Artes de la Universidad de São Paulo. Autor de «Humberto Mauro, Cinema, História», Morettin es coautor de História e Cinema: dimensões históricas do audiovisual (2 $2^{\mathrm{a}}$ ed., SP, Alameda Editorial, 2011), História e Documentário (RJ, FGV, 2012) y Visualidades Hoje (Salvador, Edufba, 2013). Miembro del Consejo de la Cinemateca brasileña desde 2007, es uno de los responsables del grupo de investigación «Historia y Audiovisual: circularidades y formas de comunicación» (http:// historiaeaudiovisual.weebly.com/). También es investigador en el CNPq (Premio de productividad nivel 2) y titular de un posdoctorado por la Universidad de París I (2012). 